\title{
BIRDS
}

\section{OSPREY BANDING PROGRAM NEAR LOON LAKE, SK, 1975 - 2002}

C. STUART HOUSTON, 863 University Drive, Saskatoon, SK S7N 0J8, E-mail: <stuart.houston@usask.ca> and FRANK SCOTT, Box 2, GS 317, Saskatoon, SK S7K 3J6.

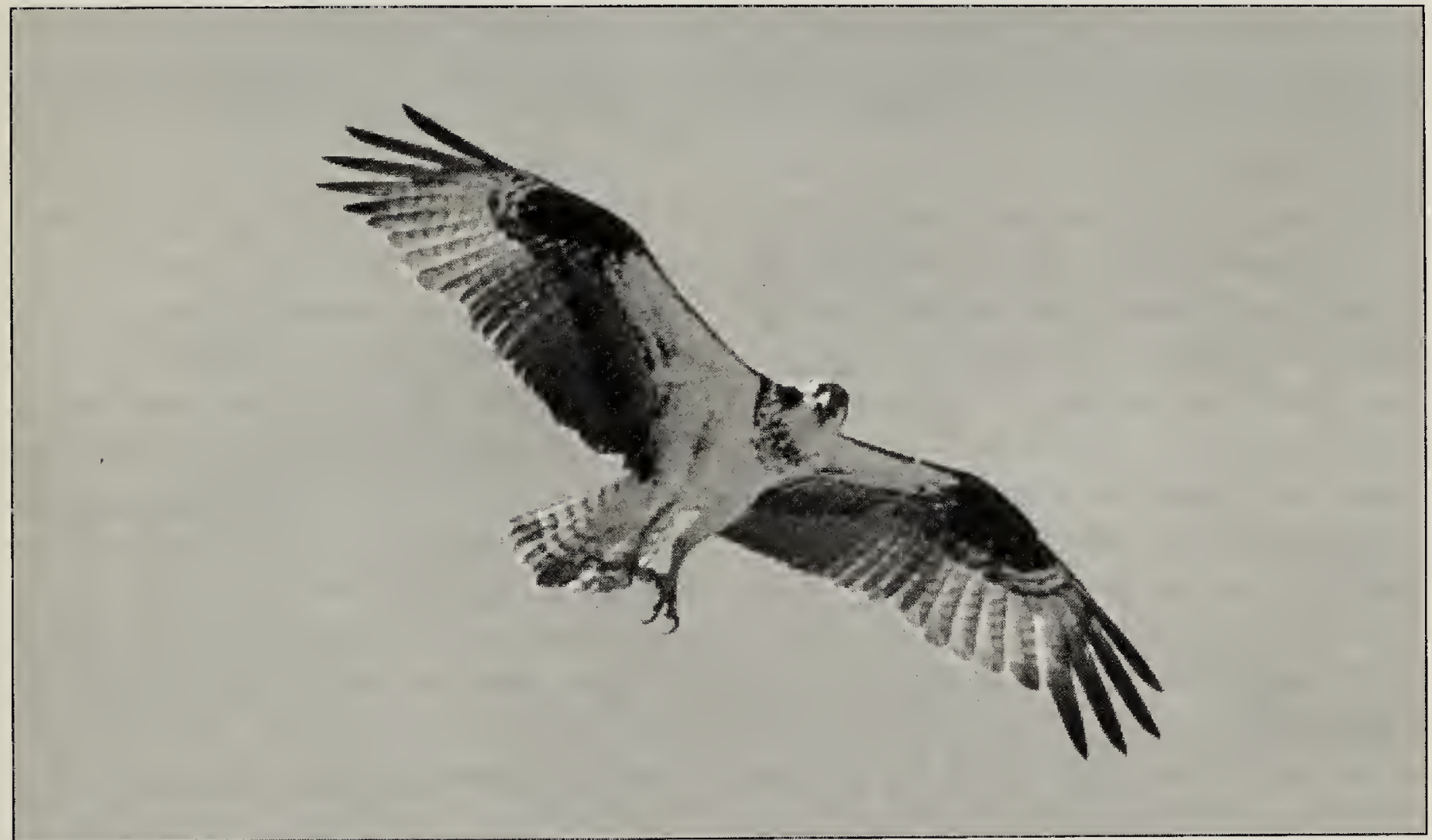

A 28-year banding study of Ospreys near Loon Lake encompassed 14 lakes and several smaller water bodies near the north ends of highways 21 and 26 in western Saskatchewan, between $53^{\circ} 45^{\prime}$ and $54^{\circ} 10^{\prime} \mathrm{N}$ and $109^{\circ} 10^{\prime}$ and $109^{\circ} 50^{\prime} \mathrm{W}$.

\section{Methods}

From 1968 to 1990 , FS searched for Osprey nests opportunistically while flying from Loon Lake to his weekly medical clinic at Ministikwan Lake, most often using a Piper Super Cub on floats. Since 1990, aerial surveys based on Loon Lake have been done only once or twice each year, checking on each of the previously known nests.

In the breeding season, nests on Galletly Lake and a slough west of Galletly Lake, were reachable only by a float-plane through 1988. Nests on Ministikwan, Peck, Murphy and Upper Makwa lakes were reached by floatplane or motor-boat, while those on Branch, Fowler and Tullibee lakes were reached by canoe.

1) Banding of Osprey nestlings, 1975 - 2002. All nest trees that were deemed safe were climbed during a weekend 
in mid- or late July, when young were about two-thirds grown.

2) Color banding of nestling Ospreys, 1988-1994. During 7 consecutive years, 145 nestlings received a color rivet band on the opposite leg to the standard USFWS aluminum band.

3) Building artificial nest structures, 1978-1994. Because Osprey nest trees eventually die and become less safe for both Ospreys and climbers, we constructed 26 platforms to replace nests in unsafe trees. We placed three of these in windmills where trees adjacent to the original nest were not solid enough for a platform to be built. ${ }^{2}$. ${ }^{3}$ We chopped down each unsafe tree containing a nest, built a platform in an adjacent solid tree or windmill and moved the contents of the previous nest onto the platform. These 26 structures were built, and sometimes subsequently refurbished, in late March.

4) Trapping of adult Ospreys on their nests, 1988-1990 and 1993. Adults were trapped on their nests, by means of an anchored, dome-shaped noose carpet placed over the nest and eggs, late in incubation. For ease of capture, 43 of the 46 trapping attempts were done on platforms. Color bands were applied quickly to the adults trapped, on the opposite leg to that with a standard aluminum band, and the adult was released at once.

\section{Results}

1) Band returns and recoveries A nestling, banded at Branch Lake in 1976, was retrapped as an adult on its nest twice, at ages 13 and 14 years, at Tullibee Lake, $21 \mathrm{~km}$ from Branch Lake.

Three Ospreys died during their first southward migration: one from Ministikwan Lake was electrocuted at Gould, Oklahoma on October 2; one from Little Fishing Lake was found dead at Fort Collins, Colorado on October 11; and one from Branch Lake was found dead at Colorado City, Texas on October 16.

The skeleton of a Loon Lake bird was found in Nebraska eight years after it was banded.

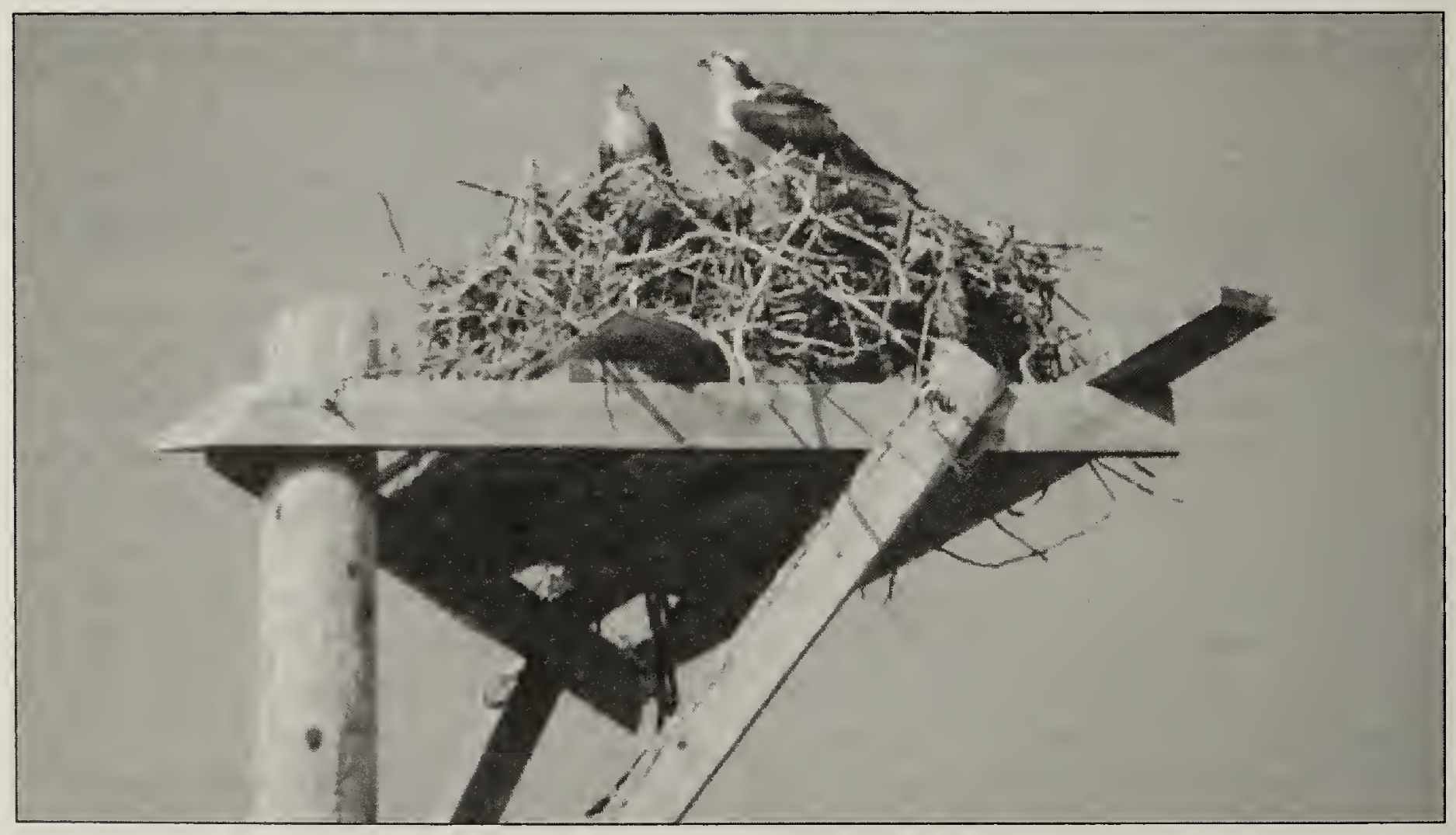




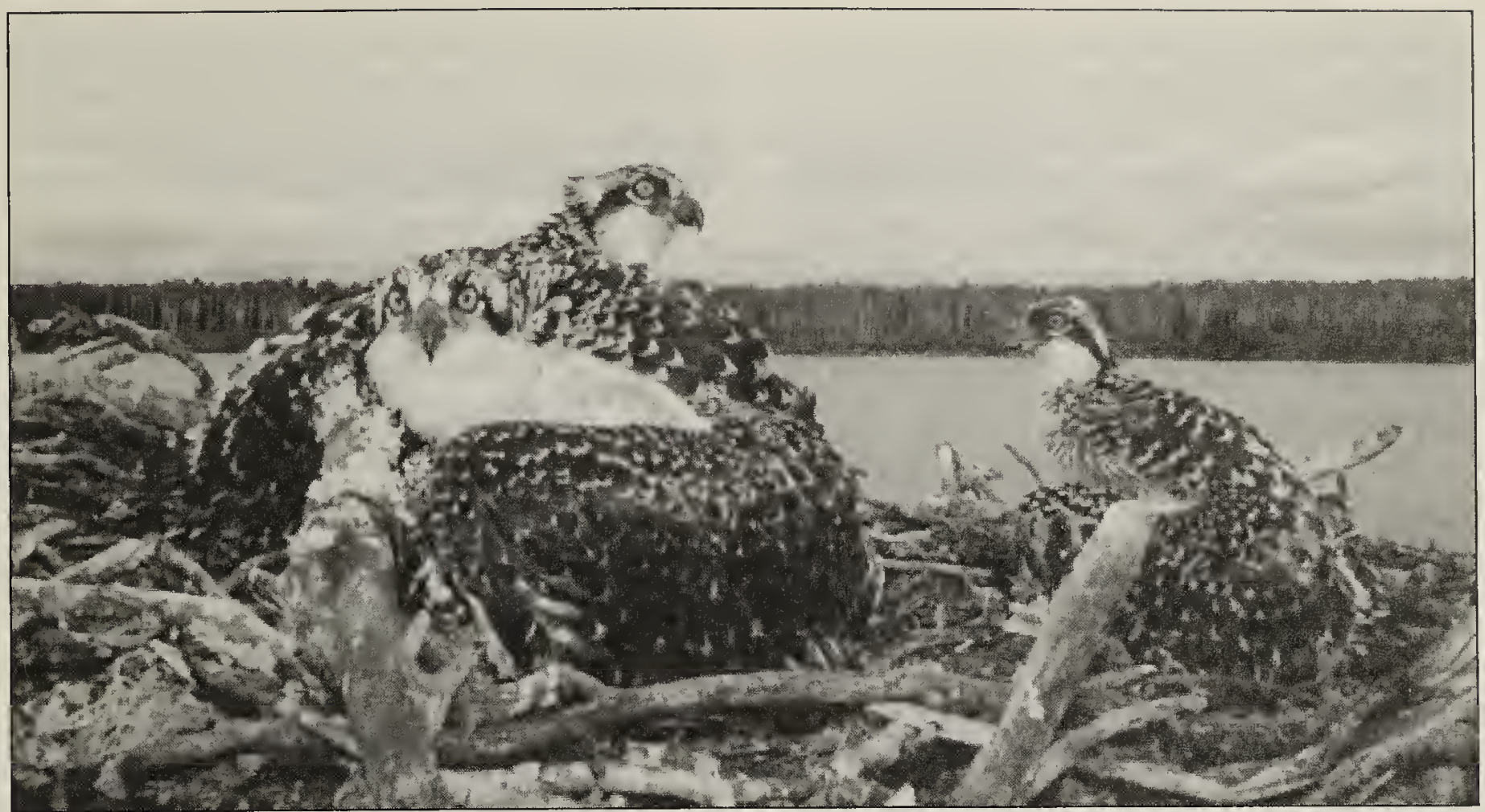

An Osprey, banded as a nestling at Ministikwan Lake on 26 July 1975, was 15 years old when found dead at the Calvin United Church camp at Lake Whitney, Alberta in July 1990. The third oldest bird, following the Tullibee Lake bird above, was from Little Fishing Lake and was hit by a car near Athabasca, Alberta, in September, at 9 years of age.

Among the five migrants that flew the farthest south, two were early arrivals in southern Central America and northern South America, on their first and only journey south: a Loon Lake bird reached Tonosi, Panama (5795 $\mathrm{km}$ ), where its band was "obtained" on 15 November and a Peck Lake bird was shot at Timbiqui, Colombia (6370 $\mathrm{km}$ ) before the end of October. A nestling banded on the north shore of Loon Lake was shot almost exactly on the equator at Atahualpa, Ecuador $(6640 \mathrm{~km})$ on 25 February of the calendar year after banding. Bands from two others, both from Peck Lake, also were obtained in the year subsequent to banding: one dates from early June at Barbacoas, Narino, Colombia $(6480 \mathrm{~km})$ and the other was found dead at Playa Guacalillos, Costa
Rica $(5385 \mathrm{~km})$ in July. The last two aluminum bands provide additional evidence of Ospreys failing to return north when one year old. ${ }^{1}$

2) Color bands on nestlings

There are four sightings of birds nesting at varying distances from their natal nest:

$0.5 \mathrm{~km}$ from its nest of origin , 9 and 12 years later (1-K Blue, adjacent nests at north end of Makwa Lake, 1994 to 2003 and 2006);

23 km, 11 years later (7-4 Red, Branch Lake to Little Jumbo Lake, 1994 to 2005); and

$30 \mathrm{~km}, 10$ years later $(\mathrm{O}-\mathrm{U}$ Blue, Ministikwan Ravine platform to Highway 99 platform, 1993 to 2003).

A fourth Osprey, wearing a blue band placed as a nestling in 1993, was twice observed $170 \mathrm{~km}$ distant, 9 and 10 years later, incubating on a platform built by Henry Tabel at Pratt Lake near Mont Nebo, SK.

A nestling with a color band from the windmill platform south of Jumbo Lake was electrocuted during fall migration eight years after banding, on the shore of the Garrison Reservoir near Pick City, ND. 
3) Trapped adults

Twelve of 27 adults wearing color bands were re-trapped in a subsequent year, ten at the nest where they had first been trapped, 9 at $1 \mathrm{yr}, 3$ at $2 \mathrm{yr}, 1$ at $3 \mathrm{yr}, 3$ at 4 years. Two adult females moved from one nest platform to a different nest platform in a subsequent year, at distances of 1.5 $\mathrm{km}$ and $12 \mathrm{~km}$. Only two band numbers were read by telescope on perched adults, one and four years after initial banding.

An adult carrying an aluminum band and a color rivet band was reported from Vera Cruz, Mexico, in a letter dated in January but with the date of finding not provided. An adult with a color band was caught by hand near Loma Bonita, Oaxaca, Mexico, in midJanuary, 61/2 years after banding.

\section{4) Artificial nest structures}

Our first six platforms, three built in 1978 and three in 1983, had only two successes. Both were built beside the site of the original nest. The other four platforms were placed randomly, without regard to Osprey territories, and remained unoccupied. All later tree platforms were constructed in a sound tree, close to an occupied tree nest in danger of falling. Of the 22 platforms that were used, the six in the western side of the study area had 13 years of success and 21 years of failure, while the 16 on the eastern side had 84 years of success and 29 years of failure.

\section{Other Observations}

Effects of fire.- The last year of this study, 2002, was noteworthy for a major forest fire that burned most of the forest, and the Osprey nests, at the north end of Makwa Lake. That year, young Ospreys in nests up to $5 \mathrm{~km}$ distant from the fire perished, possibly from smoke inhalation.
Possible adverse results from adult trapping.- The trapping of adults, the retrapping of adults in subsequent years, and eight'failed attempts to trap an adult, caused no apparent morbidity or mortality at the time, and no immediate loss of eggs. However, six to eight weeks later at the visit to band young, based on all nesting attempts with known outcome, there was a diminution in the number of young available to band at these nests, in comparison with nests where an adult had not been handled. At 23 nests, a normal complement of young was reared in spite of the trapping attempt, but there also were 22 examples of nest failure: nest fallen (2 nests), three young dead of unknown causes (2 nests), infertile eggs with no young (3 nests), or a simply failed nesting attempt (15 nests). Thus, there was a $49 \%$ failure rate after nest disturbance in comparison with an average $30 \%$ failure rate in nests not similarly disturbed. Disturbance consisted of a) climbing at the egg stage, b) temporary application of a tethered noose carpet, and c) capture of the adult.

Longevity of platforms.- Platforms in trees have a somewhat limited life, four have had to be rebuilt, two of them twice. Because of this, we now prefer to build a wooden platform on a more durable metal windmill structure.

\section{Acknowledgments}

We thank innumerable tree climbers and platform builders, but especially David G. Miller, Kelwin Wylie, Marc Bechard, Martin Gerard and Marten Stoffel. We are indebted to Marvin Brose for his assistance in locating unused windmills available for our use. We thank Julio Blas for photographing color bands on four occasions after Marten Stoffel first sighted each color band. Alan R. Poole 
and Marc Bechard provided constructive comment of an earlier version of this paper. An anonymous reviewer must be credited with many improvements.

1. EWINS, P.J. and C.S. HOUSTON. 1992. Recovery patterns of Ospreys, Pandion haliaetus, banded in Canada up to 1989. Canadian FieldNaturalist 106:361-365.
2. HOUSTON, C.S. and F.S. SCOTT. 1992. The effect of man-made platforms on Osprey reproduction at Loon Lake, Saskatchewan. Journal of Raptor Research 26:152-158.

3. SCOTT, F. and C.S. HOUSTON. 1985. Success of Osprey nest platforms near Loon Lake, Saskatchewan. Blue Jay 43:238-242.

\section{SUCCESSFUL FOSTERING OF TWO GREAT HORNED OWL CHICKS}

JARED B. CLARKE, 323 Habkirk Drive, Regina, SK S4S 6A9. E-mail: <clarkejared16@yahoo.ca>

At noon on May 19, 2007, I received a phone call from Doug Kemp concerning an active Great Horned Owl nest in his yard in the town of Pasqua, SK. That morning, a SaskPower employee notified Doug that a Great Horned Owl had landed on the transmitter box approximately $50 \mathrm{~m}$ from his home and had been killed. Three weeks earlier, Doug had found an adult owl in his yard that had apparently died from natural causes. Presuming that both parents were now dead and the owlets were orphaned, Doug collected the two chicks, approximately 5 weeks old and in good condition, and brought them to me in Moose Jaw.

After discussing options with Stuart Houston, who in past years had successfully fostered single orphaned owls into active nests, I decided to do the same. I wanted to place each of the orphaned chicks into a nest containing only one chick, but of the 32 active nests in the Regina and Moose Jaw area that I had found in spring, I knew of only one that contained a single chick. While banding that owlet (\#788-56510, hereafter \#10) on May 6 , I found that its nest was overflowing with food: the remains of two Gray Partridge, one Blue-winged Teal, a Richardson's Ground-squirrel, a Western Meadowlark, a sandpiper and a Shorteared Owl. I chose to place both owlets into this nest, as adding two chicks would not exceed the normal clutch size (2 to 3 ) for this species and the abundance of food suggested the adults should be capable of providing for all three chicks.

On the evening of May 20, 2007, Elizabeth Travis and I placed the two orphans (band \#788-56563 \& 78856564, hereafter \#63 \& 64) into this nest. Owl \#10 was easily distinguished from \#63 \& 64, as it was a week and a half older and its feathers were quite orange compared to the paler-gray, younger birds. (See inside front cover.) This difference was apparent from our viewing point on the highway, $150 \mathrm{~m}$ away.

All three chicks remained in the nest for the next 6 days. On the morning of May 27, the nest was empty but two chicks were located nearby in different trees: bird \#10 and one of the orphans. The orphan had the back end of a duck cached beside it, which indicated that the adults had accepted the orphaned 